\title{
Planned Treatment Administration Rate
}

National Cancer Institute

\section{Source}

National Cancer Institute. Planned Treatment Administration Rate. NCI Thesaurus. Code C161577.

The planned amount of treatment per unit of time during a single administration. 